\title{
UMA INSTITUIÇÃO DE ENSINO SUPERIOR NA FORMAÇÃO DE PROFESSORES: UMA METÁFORA CONSTRUÍDA POR DENTRO
}

\author{
AN INSTITUTION OF HIGHER EDUCATION IN TEACHER TRAINING: \\ A METAPHOR BUILT WITHIN
}

\section{UNA INSTITUCIÓN DE ENSEÑANZA SUPERIOR EN LA FORMACIÓN DE PROFESORES: UNA METÁFORA CONSTRUIDA POR DENTRO}

\section{Pedro Duarte \\ Fernando Diogo}

\begin{abstract}
RESUMO: O presente trabalho visa, através da análise de 32 inquéritos, verificar a possibilidade de construir uma metáfora explicativa, tendo por base a perspectiva dos inquiridos. Pretende-se, mais do que dar uma visão externa da Instituição do Ensino Superior de Formação de Professores em análise, perceber qual é a perspectiva dos diferentes elementos que a compõem. Deste modo, na fase inicial, optou-se por, sumariamente, explorar as várias perspectivas e visões possíveis da escola e das organizações educativas. Para desenvolver esse processo, utilizaram-se os modelos/ metáforas tradicionais de análise das organizações. Numa fase posterior, exploram-se os dados resultantes dos inquéritos para verificar que tendências significativas poderiam servir de base para a (re)construção de uma metáfora explicativa do funcionamento da Instituição do Ensino Superior de Formação de Professores estudada. A análise, tendo em conta o número de elementos da amostra e o instrumento de recolha de dados utilizado, foi, no seu essencial, sustentada numa perspectiva quantitativa. Na fase final, e face aos dois aspetos anteriores, propõe-se uma metáfora que seja capaz de explicar, tomando por base a perspectiva dos inquiridos, a forma como a Instituição de Ensino Superior de Formação de Professores se estrutura, organiza e funciona: A Escola como Casa na Árvore.
\end{abstract}

PALAVRAS-CHAVE: Metáfora. Organizações educativas. Formação de professors.

ABSTRACT: The present work aims, through the analysis of 32 surveys, to verify the possibility of constructing an explanatory metaphor, based on the perspective of the respondents. It is intended, rather than giving an external view of the Institution of Higher Education Teacher Training under analysis, to perceive the perspective of the different elements that compose it. Thus, in the initial phase, it was decided to briefly explore the different perspectives and possible visions of the school and educational organizations. In order to develop this process, traditional models / metaphors of organizational analysis were used. At a later stage, the data from the surveys were explored to verify that significant trends could serve as a basis for (re) constructing a metaphor that explains the functioning of the Institution of Higher Education for Teacher Education studied. The analysis, taking into account the number of sample elements and the data collection instrument used, was essentially based on a quantitative perspective. In the final phase, and in the face of two previous aspects, it is proposed a metaphor that is able to explain, based on the perspective of the respondents, a way in which a higher education institution of Teacher Training structures, organizes and functions: School as Tree House.

KEYWORDS: Metaphor. Educational organizations. Teacher training.

RESUMEN: El presente trabajo pretende, a través del análisis de 32 encuestas, verificar la posibilidad de construir una metáfora explicativa, teniendo como base la perspicacia de los encuestados. Se pretende, más que dar una visión externa de la Institución de la Enseñanza Superior de Formación de Profesores en análisis, percibir cuál es la perspectiva de los diferentes elementos que la componen. De este modo, en la fase inicial, se optó por, sumariamente, explorar las diferentes perspectivas y visiones posibles de la escuela y de las

${ }^{1}$ Submetido em: 01/11/2017 - Aceito em: 18/12/2017 - Publicado em: 08/01/2018.

\begin{tabular}{|l|c|c|c|c|c|} 
(C) Rev. Inter. Educ. Sup. & Campinas, SP & v.4 & n.1 & p.197-220 & jan./abr. 2017
\end{tabular}


organizaciones educativas. Para desarrollar este proceso, se utilizaron los modelos / metáforas tradicionales de análisis de las organizaciones. En una fase posterior, se explotan los datos resultantes de las encuestas para verificar qué tendencias significativas podrían servir de base para la (re) construcción de una metáfora explicativa del funcionamiento de la Institución de la Enseñanza Superior de Formación de Profesores estudiada. El análisis, teniendo en cuenta el número de elementos de la muestra y el instrumento de recogida de datos utilizado, se basó esencialmente en una perspectiva cuantitativa. En la fase final, y frente a dos aspectos anteriores, se propone una metáfora que sea capaz de explicar, tomando como base la persuasión de los encuestados, una forma como una institución de enseñanza superior de Formación de Profesores se estructura, organiza y funciona: A Escuela como Casa en el Árbol.

PALABRAS CLAVE: Metáfora. Organizaciones educativas. Formación de profesores.

\title{
AS MEtáforaS COMO MOdelOS eXPlicativos dAS ORGANIZAÇões EDUCATIVAS
}

De acordo com o que é apresentado por Jensen (2006), as metáforas ${ }^{2}$ são, desde a Antiguidade, um modelo comum que possibilita a explicação e a compreensão de conceitos complexos, nomeadamente fenómenos sociais e educativos. Tendo isso em consideração, no âmbito das ciências sociais, as metáforas são, por vezes, o foco principal da análise, afirmando-se como o centro da teoria, sobre a qual é possível condensar a explicação do funcionamento e organização da sociedade e do espaço social (SOREANU, 2010). Com a sua utilização é possível construir significado sobre os contextos, através da construção de paralelismos entre os diversos aspetos que se encontram em análise (MORGAN, 2002). Desta forma, as metáforas apresentam a potencialidade de explicar as situações sociais fazendo uso da articulação de diferentes pontos de vista (MOUTINHO, 2012) e diversos domínios, afirmando-se como um processo de criação de conhecimento, promovendo a emancipação do mesmo (CRAIG, 2005; SOREANU, 2010).

Através do trabalho de Morgan (2002), fica claro que as metáforas utilizadas no contexto das ciências sociais têm especial relevância como modelos explicativos das organizações e da forma como elas são administradas. Nas palavras do autor,

\begin{abstract}
toda a teoria e prática da organização e da administração baseia-se em imagens, ou metáforas, que nos levam a entender situações de maneira eficaz, mas parcial. Quando nos damos conta disto, aprendemos a reconhecer que modos que escolhemos para administrar e organizar nos levam a perder a oportunidade de usar outros modos de administrar e organizar. Além disso, reconhecemos que, como toda metáfora tem vantagens e tem limitações, precisamos estar sempre conscientes da existência de pontos cegos que prejudicam nossa eficácia (p.20).
\end{abstract}

\footnotetext{
${ }^{2}$ Rodrigues (2007) considera que há uma relação próxima (no âmbito da sua utilização para a produção de conhecimento científico no contexto das ciências sociais) entre os conceitos: analogia, metáfora e modelo. Mesmo salvaguardadas as diferenças entre os conceitos, tendo em conta o âmbito e dimensão do trabalho, utilizar-se-ão as três palavras como homólogas.

(C) Rev. Inter. Educ. Sup. $\quad$ Campinas, SP

v.4

n. 1

p.197-220 jan./abr. 2017
} 
Como é referido por Nóvoa (1992), o estudo das escolas, enquanto organizações educativas, tem sido particularmente relevante para a compreensão e intervenção no âmbito das ciências da educação. À luz do que é apresentado por Lima (2008a; 2008b), mesmo com a ascensão de uma sociologia das organizações educativas, reconhece-se que os modelos organizacionais, de carácter sociológico formal, são decisivos tanto na forma como as organizações educativas são estruturadas e administradas, como no modo como é feita a interpretação desses processos. Acrescenta-se, ainda, que a análise de carácter qualitativo, sustentada nas metáforas, tem sido amplamente aceite, metodológica e etimologicamente, no contexto das disciplinas das ciências da educação, como método de investigação educativa (CRAIG, 2005; JENSEN, 2006). Assim, as metáforas, no âmbito da análise das escolas, possibilitam estudar a forma como a estrutura escolar é compreendida e a forma como os indivíduos atuam no interior da instituição educativa (BRANDT, 2004).

Face a esse pressuposto, e tendo em conta os trabalhos de Cunha (1995), Costa (1996), Morgan (2002) e Brandt (2004), considerar-se-á que as organizações educativas podem ser encaradas de acordo com seis modelos específicos: i) modelo racional; ii) modelo cognitivo; iii) modelo orgânico; iv) modelo cultural; v) modelo humano; vi) modelo político.

\section{MOdElo RACIONAL: A eSCOLA COMO MÁquina OU A ESCOLA COMO EMPRESA}

Este modelo retoma os estudos desenvolvidos por Taylor e Weber, dos inícios do século passado, em que os autores focavam a sua análise das organizações numa perspectiva técnica, que visa a melhoria da eficácia, eficiência (MORGAN, 2002; BRANDT, 2004; TAN, HEE e PIAW, 2015) e competência (CHIAVENATO, 1987). Esta perspectiva articula, por um lado, a Teoria Clássica da Administração e, pelo outro, a Teoria da Burocracia (COSTA, 1996; MOUTINHO, 2012).

Reconhece-se que esta analogia, em algumas situações, ignora a componente humana das instituições, destacando, essencialmente, a racionalidade aí presente e os procedimentos de natureza técnica/tecnicista, privilegiando os processos mecânicos (FERREIRA, 2004) e de especialização (CHIAVENATO, 1987). Face ao exposto, percebe-se que as organizações desta tipologia irão, com significativa relevância, edificar a estrutura organizacional numa base hierárquica, de forte cariz burocrático - através de regras e regulamentos -, em que se enfatiza a impessoalidade, a formalidade das relações e a especialização do trabalho (COSTA, 1996; MORGAN, 2002; FERREIRA, 2004; MOUTINHO, 2012).

Salienta-se, ainda, que as organizações com este tipo de modelo apresentam dificuldades na forma como lidam com a inovação e com a criatividade (MORGAN, 2002; BRANDT, 2004), 
uma vez que o processo criativo e inovador é, também ele, previsto de forma burocrática e técnica (FERREIRA, 2004), como uma espécie de inovação por decreto (COSTA, 1996).

De acordo com o que é apresentado por Meyer, Scott e Deal (1980), historicamente as escolas são marcadas pelo carácter formal, desenvolvendo-se como organizações estruturadas pelo pensamento racional e burocrático. Ressalva-se, porém, que, de acordo com os mesmos autores, essas dimensões são impostas às escolas, pelas forças socais externas às mesmas.

Face ao que é explicado por Costa (1996), fica claro que a transposição deste modelo para as organizações educativas acarreta distintas perspectivas que têm implicações diretas na escola em dois domínios diferentes: a orgânica e as abordagens pedagógicas.

No primeiro domínio, tender-se-á a defender uma perspectiva taylorista da educação, na qual se perpetua a uniformidade (do currículo, das aulas, das turmas, dos espaços educativos e dos horários), a impessoalidade (dentro da comunidade escolar e entre a comunidade escolar e o seu exterior); a hierarquia (cargos unipessoais e a centralização de decisões no diretor) e a burocracia (planificação minuciosa; cumprimento de normas e prevalência de documentos escritos) (COSTA, 1996; FERREIRA, 2004; MOUTINHO, 2012). Numa perspectiva homóloga, Meyer, Scott e Deal (1980) consideram que, uma escola com estas características necessita, para sobreviver, de se adequar às normas instituídas. Estas escolas constroem-se e organizam-se de forma a aproximarem-se do princípio da Teoria da Administração Científica (COSTA, 1996) - segundo a qual a escola é, efetivamente, concebida como uma empresa (educativa) que, como uma organização técnico-burocrática, promove, entre outros valores, a eficácia, eficiência, otimização e a produtividade (FERREIRA, 2004).

No segundo domínio prevalece uma visão pela qual os alunos são encarados como matériaprima e os professores como trabalhadores técnicos (COSTA, 1996) e burocráticos (FERREIRA, 2004). Face a este pressuposto, a ação pedagógica centrar-se-á na uniformização do processo de ensino (COSTA, 1996), numa ação docente sustentada numa pedagogia uniforme (FERREIRA, 2004). A par disso, o processo educativo constrói-se com base numa pedagogia por objetivos, remontando às perspectivas de Taylor, num entendimento que, aliado ao desenvolvimento da pedagogia científica, promove a valorização de conceitos como rendimento do ensino e eficácia das aprendizagens (COSTA, 1996).

\section{MODELO COGNITIVO: A ESCOLA COMO CÉREBRO}

O Modelo Cognitivo compara o funcionamento das organizações ao funcionamento de um cérebro (NICOLINI, 1999; MORGAN, 2002) sendo os aspetos cognitivos encarados como elementos intrínsecos ao funcionamento das organizações (SCHNEIDER; ANGELMAR, 1993). Morgan (2002, p.95) refere que "as organizações são sistemas de informações. São sistemas de comunicações. E são sistemas de tomada de decisões. Portanto não é um exagero 
considerá-las como cérebros processadores de informações" Compreende-se, tomando por base o que foi exposto, que, de acordo com este modelo, se enfatize o processo de recolha de informação, interna e externa às organizações para que, através da sua análise racional, seja possível tomar decisões fundamentadas nos dados recolhidos (MORGAN, 2002; BUSH, 2006).

Porém, os dados recolhidos não são o fator exclusivo para o funcionamento da organização. É fundamental recordar que as pessoas são agentes ativos no processo de tratamento da informação, possibilitando, por isso, a construção, por parte dos intervenientes, de uma realidade organizacional (CUNHA, 1995). Esta realidade, construída e partilhada socialmente, pode ser encarada como um sistema cognitivo, através do qual é possível estabelecer uma base comum de compreensão e comunicação entre os diferentes intervenientes organizacionais (NICOLINI, 1999).

Nesta metáfora assume-se que as ações tomadas pelas organizações são fruto de um fenómeno cognitivo (SCHNEIDER; ANGELMAR, 1993; NICOLINI, 1999). As organizações são desta forma, estruturadas e desenhadas tomando em consideração, por um lado, a necessidade de organizar as informações e, pelo outro, os fatores que interferem no processo de tomada de decisões (BASTOS, SOUZAB, et al., 2007). Este tipo de estruturas assemelha-se, nas organizações maiores e mais complexas, ao funcionamento de um cérebro, como já se tinha referenciado.

Para melhor corresponder ao funcionamento destas organizações é necessário desenvolver processos informatizados que possibilitem o controlo e circulação dos dados, como análises financeiras, relatórios de vendas, stocks, entre outros. Face ao apresentado, reconhece-se que, de acordo com este modelo, as organizações sofrem um processo de transformação, alicerçando a sua ação em sistemas de informação que acabam por substituir as interações humanas (MORGAN, 2002). Estas mudanças estão marcadas, significativamente, pelo processo de globalização, o que permite o trabalho colaborativo de/entre diferentes equipas dispersas geograficamente (HODGKINSON; HEALEY, 2008).

Em concordância com o apresentado, à necessidade de desenvolver mecanismos computacionais que possibilitem a circulação de informação entre os diferentes grupos no interior da organização revela ser uma dimensão extremamente significativa no contexto da perspectiva cognitiva (MORGAN, 2002; HODGKINSON e HEALEY, 2008). Valorizam-se assim, os aspetos computacionais, uma vez que através deles é possível recolher dados e fazer circular as informações.

Outro aspeto proeminente nesta metáfora é a importância que se dá à possibilidade que as organizações têm de aprender, mudar e desenvolver-se (SCHNEIDER; ANGELMAR, 1993; MORGAN, 2002; SCHWANINGER, 2003; HODGKINSON; HEALEY, 2008). O processo de aprendizagem requer o reconhecimento que o ato de aprender é um ato cognitivo, no qual 
se procede ao autorreconhecimento e à auto-organização (SCHWANINGER, 2003). Esse processo é marcado pela avaliação contínua, sustentada na autocrítica e na investigação da própria organização em que os intervenientes se auto organizam e aprendem (MORGAN, 2002).

Transpor este modelo para a escola implica garantir, valorizando os recursos informáticos, a recolha de informação e a sua comunicação entre os diferentes grupos, para que cada um deles se possa auto organizar de forma a melhor responder às necessidades da organização educativa. A par disso envolve a necessidade de, no contexto escolar, se perceber a importância da auto avaliação e da autocrítica no processo de mudança e de adaptação da escola.

\section{MODELO ORGÂNICO: A ESCOLA COMO ORGANISMO VIVO}

Esta metáfora assenta na premissa que as organizações sociais apresentam atributos homólogos aos dos seres vivos. Como assinala Bertalanffy (1969, p.45), as características da "organization, whether of a living organism or a society, are notions like those of wholeness, growth, differentiation, hierarchical order, dominance, control, competition, etc". Face ao apresentado, reconhece-se que esta perspectiva incide, essencialmente, nos aspetos que aproximam as organizações sociais aos organismos vivos e à forma, biológica, como eles são analisados. Desta forma, e tal como acontece com os seres vivos, também o objetivo fundamental das organizações é a sobrevivência (FROTA, 2011) e, tal como em relação aos seres vivos, a sobrevivência depende da adaptação ao ambiente externo.

O modelo orgânico das organizações permite enfatizar os aspetos organizativos relacionados com a importância da adaptação e satisfação das necessidades das instituições, percepcionando as organizações como se de organismos se tratassem (MORGAN, 2002; FERREIRA, 2004). Esta metáfora revela, assim, os aspetos relacionados com as relações intra e inter-organizacionais, incidindo, com especial interesse, nos processos de adaptação ao meio (FERREIRA, 2004) que se apresentam como constantes e essenciais no interior da organização (BRANDT, 2004).

Tendo em conta esta perspectiva, é possível, por um lado, perceber a importância do meio/ambiente e a forma como este contribui para os processos de mudança e de adaptação das instituições e, pelo outro, percepcionar os aspetos inter-relacionais das organizações, marcados pelos diferentes intervenientes: seres humanos, negócios e necessidades técnicas (MORGAN, 2002; BRANDT, 2004).

Esta analogia, além do que já foi explorado, enfatiza a importância da comunicação no interior da organização. Através do processo de comunicação entre os departamentos, a instituição possibilita a construção de pontes comunicativas que permitirão a colaboração 
entre os vários elementos na resolução de problemas e na inovação organizacional (MORGAN, 2002). Este foco de análise permite encarar as organizações como um "sistema aberto, como um conjunto de partes inter-relacionadas e interdependentes, de modo a formarem um todo unificado numa determinada envolvente" (FROTA, 2011, p. 14).

Numa nota final, é ainda necessário alertar que a Teoria da Evolução das Espécies de Darwin também ajuda a explicar diferentes elementos de análise das organizações: a sua diversidade; os fatores de influência do número e distribuição; a relação com o ambiente; o processo evolutivo; a adaptabilidade, extinção e sobrevivência das organizações. Desta forma, há uma constante tensão entre o meio e as organizações, exigindo que estas se adaptem para que tenham forma de sobreviver (MORGAN, 2002; FERREIRA, 2004).

Tendo em consideração o que foi apresentado, transitar este modelo para a análise escolar pressupõe a compreensão da escola como um organismo vivo. Desta forma, de acordo com esta metáfora, os diversos departamentos educativos deverão trabalhar em conjunto para um objetivo comum, a sobrevivência da escola.

Se pretende sobreviver e prosperar, entenda-se continuar a captar e educar novos estudantes, as escolas e demais instituições educativas precisam de se adaptar ao contexto em que se encontram inseridas. A par disso, terão que evoluir de forma a, em comparação com outras organizações educativas, dar uma melhor resposta aos estímulos externos. Ainda assim, é necessário que trabalhem em colaboração com as diversas organizações para, em conjunto, conseguirem sobreviver ao ambiente que é dinâmico e instável.

\section{MODELO CULTURAL: A ESCOLA COMO CULTURA}

A metáfora cultural considera que a cultura, além de ser uma construção e um facto social é, também, um elemento organizacional enquanto sistema sócio-estrutural (MORGAN, 2002; FERREIRA, 2004).

Este modelo possibilita a análise organizacional centralizada na cultura das instituições (MORGAN, 2002), o que permite a compreensão de aspetos qualitativos das diferentes organizações (BUSH, 2006), com especial impacto na análise das organizações educativas (TORRES, 2007).

De acordo com Morgan (2002, p. 136-137), esta "metáfora ajuda a repensar quase todos os aspectos do funcionamento corporativo, inclusive a estratégia, a estrutura e a natureza da liderança e da administração".

Este modelo reconhece que a cultura não é um elemento estanque, mas resultado contínuo da ação humana sobre a realidade. De acordo com esta analogia, a cultura é encarada como uma atividade, vivida e vivenciada pelos seus agentes, através da qual as pessoas (re) constroem 
significado sobre o ambiente em que vivem (MORGAN, 2002; FERREIRA, 2004). Em concordância com estes pressupostos, à cultura surge como a interpretação e a compreensão comum da realidade e do próprio comportamento coletivo (MORGAN, 2002), que confere o sentido de missão e identidade aos trabalhadores de uma determinada instituição (TAN, HEE, PIAW, 2015), fazendo com que a organização, enquanto coletivo, seja, também ela, produtora de realidades sociais (BRANDT, 2004).

Face ao referido, compreende-se que a cultura, no âmbito das organizações, permite a compreensão da organização informal e da dinâmica interna das instituições, em contraponto à racionalidade das análises modernas, uma vez que se valorizam os aspetos simbólicos (FERREIRA, 2004; TAN, HEE e PIAW, 2015). Reconhece-se ainda que, através da análise da cultura organizacional e aceitando a sua transformação interna, é possível explicar o processo de mudança das organizações, pela transformação cultural (MORGAN, 2002).

Este modelo implica reconhecer que as escolas, e restantes instituições de ensino, são construções sociais, nas quais os indivíduos se afirmam como essenciais para a construção e sustentação dos valores e práticas (BRANDT, 2004; TRIGO; COSTA, 2008), integradas num coletivo dentro da organização (FERREIRA, 2004). Esta metáfora permite encarar a escola como uma mini sociedade, caracterizada pelas suas dimensões culturais únicas e distintivas das demais (FERREIRA, 2004), sendo possível reconhecer as suas especificidades, marcadas pelas manifestações simbólicas, como os valores, a linguagem, as cerimónias e os rituais (COSTA, 1996; FERREIRA, 2004).

Em concomitância com estes pressupostos, as escolas eficazes serão aquelas que constroem e apresentam uma cultura forte e dinâmica, com base na qual a ação escolar é sustentada e desenvolvida (COSTA, 1996; FERREIRA, 2004). Os conceitos de qualidade e excelência ganham especial relevância (COSTA, 1996; FERREIRA, 2004; TORRES, 2007). Estes conceitos relacionam-se com a forma como todos os intervenientes da comunidade escolar se apropriam da cultura da organização e contribuem para o seu fortalecimento. Compreende-se, portanto, que a escola adquire características de qualidade e excelência quando torna a cultura escolar como o núcleo duro de ação da/na instituição, na qual há uma convergência de todos (COSTA, 1996).

Face a esta perspectiva, tanto a prática pedagógica, como a ação dos estudantes, deve espelhar a cultura/imagem da escola e proporcionar momentos que possam contribuir para o seu fortalecimento, reconstrução e mudança.

\section{MODELO HUMANO: A ESCOLA COMO DEMOCRACIA}

Retomando as perspectivas da teoria das relações humanas, assume-se como necessário democratizar e humanizar as organizações (CHIAVENATO, 1987). Neste sentido, Morgan 
(2002, p. 56) identifica que "as atividades do trabalho são influenciadas (...) pela natureza dos seus humanos". Reconhece-se, de acordo com este modelo, a importância de, no âmbito da análise organizacional, valorizar a componente humana presente em todas as organizações.

Os trabalhos de Abraham Maslow elucidam a forma como as necessidades humanas básicas influenciam a maneira de cada um agir no seu dia-a-dia. Tendo em consideração as suas investigações, reconhece-se a importância de, no interior da organização, valorizar-se as necessidades dos trabalhadores, para se promover, em todos os intervenientes, o envolvimento e compromisso para com a organização (MCGREGOR, 1957; MORGAN, 2002; BRANDT, 2004; TAN, HEE, PIAW, 2015). Face ao exposto, compreende-se que, de uma forma muito particular, esta metáfora privilegia o indivíduo como unidade organizacional mínima (FERREIRA, 2004), sendo essencial que a organização se preocupe com os seus colaboradores, valorizando o seu bem-estar e as relações sociais no interior da instituição, preocupando-se com as necessidades e interesses de cada um (MCGREGOR, 1957; MORGAN, 2002; TAN, HEE, PIAW, 2015). A organização só conseguirá motivar e implicar os intervenientes se responder conveniente e hierarquicamente a essas necessidades (MCGREGOR, 1957).

Numa abordagem geral e sumária, é possível considerar-se que «as organizações são aquilo que elas significam para cada um dos membros e resultam da interacção entre eles» (FERREIRA, 2004, p. 109).

Com base no que foi aludido, compreende-se que os objetivos organizacionais deixam de estar à margem dos objetivos individuais das pessoas que a constituem (MORGAN, 2002; FERREIRA, 2004; TAN, HEE e PIAW, 2015), uma vez que, em concordância com este pressuposto, os indivíduos não se limitam a pertencer a uma organização, eles são a própria organização (FERREIRA, 2004). Considera-se essencial que as ações desenvolvidas no contexto da instituição possam, simultaneamente, beneficiar as organizações e os elementos que a constituem (TAN, HEE, PIAW, 2015). Esta metáfora implica uma gestão que rompa com um estilo de liderança limitativa, autoritária e desumanizadora (MORGAN, 2002), que encoraja a passividade e condiciona a responsabilidade dos elementos da organização.

Numa nota final, face ao que foi explorado e por não se ter encontrado referências que apresentassem uma metáfora sustentada, optou-se por considerar que este modelo possibilita a construção da metáfora escola como democracia (COSTA, 1996). Escolheu-se esta metáfora, uma vez que se observa que a democracia é um dos conceitos que melhor corporiza o modelo humano, porque o processo democrático, implícita e imperiosamente, se toma em consideração as necessidades dos seus intervenientes, e porque, como recorda Chiavenato (1987), os processos democráticos encontram-se inerentes às teorias humanas das organizações. Deste modo, de acordo com esta metáfora, a escola terá de considerar os interesses e necessidades dos professores, estudantes, pessoal não docente e restante a

\begin{tabular}{|l|c|c|c|c|c|}
\hline (C) Rev. Inter. Educ. Sup. & Campinas, SP & v.4 & n.1 & p.197-220 & jan./abr. 2017 \\
\hline
\end{tabular}


comunidade escolar, para que consiga criar uma atmosfera que seja propícia para o trabalho, motivadora e que envolva e implique as pessoas com (e na) escola.

\section{MODELO POLítico: A ESCOLA COMO ARENA POLítiCA}

Outra metáfora possível é a análise das organizações e das administrações como um processo político, no qual é possível identificar o fenómeno de politização das instituições e dos seus modelos de gestão. Compreende-se esta metáfora ao ter-se em consideração que "as organizações são fenómenos sociais e políticos enquanto responsáveis pela ordem e pela autoridade e estão destinadas a dirigir pessoas que possuem interesses, por vezes opostos e conflituantes".

De acordo com este modelo, o poder e a forma como ele é obtido, exercido e mantido desempenham um importante papel no interior da organização (MORGAN, 2002), fazendo com que os líderes se apresentem como pessoas extremamente influentes, que dedicam o seu tempo a criar relações (e alianças) e a negociar, sustentando o seu poder, no interior da organização, na base da influência e da negociação (TAN, HEE, PIAW, 2015). Compreendese, portanto, que as formas de poder, no âmbito desta metáfora, é resultado, por um lado, da autoridade formal e, pelo outro, da influência das frações internas e da negociação entre os grupos de poder/influência (MORGAN, 2002; FERREIRA, 2004).

Face a esta metáfora, os interesses e os conflitos de interesses são intrínsecos à organização (MORGAN, 2002; BRANDT, 2004; FERREIRA, 2004; FROTA, 2011), porque eles são fruto da ação social dos diferentes intervenientes (TAN, HEE, PIAW, 2015), agindo cada um de acordo com interesses próprios (FERREIRA, 2004). Contudo, de acordo com esta metáfora, eles não se apresentam como disfuncionais.

Ainda que inevitáveis, tendo em consideração a dimensão política das organizações, os confrontos poderão servir e promover situações de mudança e evolução (MORGAN, 2002; FROTA, 2011), uma vez que a tomada de decisões, no âmbito de modelo, é construída na base dos grupos e nos seus interesses, através de processos de confronto, alianças e negociação (FERREIRA, 2004; BRANDT, 2004).

De acordo com este modelo, e em simultaneidade com os pressupostos já abordados, a escola é encarada como um sistema político que replica a forma de funcionamento e as situações políticas homólogas aos contextos sociais macroestruturais (COSTA, 1996), em que os departamentos de professores, ou outros grupos, são considerados centros de poder/influência (FERREIRA, 2004). 
Desta forma, e tendo por base os trabalhos de Costa (1996) e Bush (2006) ${ }^{3}$, a escola, como organização educativa, sustenta-se em quatro domínios diferentes: interesses; conflito; poder; negociação.

\section{UMA INSTITUIÇÃO DE ENSINO SUPERIOR NA FORMAÇÃO DE PROFESSORES: UMA METÁFORA CONSTRUÍDA POR DENTRO}

Como têm sido explorado por diferentes autores, como Duarte (2016), as instituições de Ensino Superior são elementos basilares na formação de professores, seja na formação inicial, seja na formação contínua dos docentes.

Reconhecendo essa importância, optou-se por estudar uma Instituição de Ensino Superior (IES) de Portugal, que tem um antecedente histórico que remonta ao século XIX. O presente trabalho tem como objetivo, à semelhança do que é aludido por Soreanu (2010), construir uma metáfora explicativa de uma determinada organização educativa.

Face ao exposto, é possível considerar-se que o presente artigo pode ser enquadrado como um estudo de caso (BASSEY, 2003) e que a técnica utilizada para a recolha de dados foi o inquérito por questionário.

De acordo com Coutinho (2013), o inquérito por questionário é uma técnica de recolha de dados através de um formulário, que possibilita ao investigador inquirir um número elevado de pessoas, facilitando a análise quantitativa. É tendencialmente utilizado quando se pretende analisar amostras com um número elevado de pessoas, sendo por isso essencial ter em atenção a constituição da mesma, para que esta tenha validade científica.

Face ao objetivo do trabalho, optou-se por entregar o inquérito a uma amostra que possibilitasse recolher dados suficientes para proporcionar a análise da organização. Mesmo reconhecendo-se que a amostra não possibilita uma generalização dos dados, apenas foram considerados 32 inquéritos por questionários. O objetivo desta recolha é analisar, sumariamente, as perspectivas dos próprios intervenientes da IES em estudo, de modo a que seja possível construir uma metáfora organizacional da instituição.

Os inquéritos por questionários analisados foram preenchidos, como já foi mencionado, por 32 pessoas: 11 docentes; 9 discentes; 12 não docentes.

O inquérito por questionário foi divido em duas questões. Na primeira questão, os inquiridos escolhiam, dentro da totalidade das 18 frases conotadas com os modelos anteriormente apresentados (confrontar com Apêndice 1), aquelas que consideravam ser representativa da

\footnotetext{
${ }^{3}$ Embora este autor considere 6 domínios diferentes, no seu essencial podem ser reestruturados em 4 grandes domínios, homólogos aos apresentados por Costa (1996).
}

(C) Rev. Inter. Educ. Sup.

Campinas, SP

v.4

n. 1

p.197-220

jan./abr. 2017 
IES em estudo. A segunda questão, por sua vez, pedia que, no confronto de duas frases diferentes, os inquiridos escolhessem aquela que, na sua opinião, melhor caracterizasse a IES.

\section{APRESENTAÇÃO E ANÁLISE DOS RESULTADOS}

A apresentação dos resultados irá incidir, essencialmente, nos dados recolhidos através da primeira questão, uma vez que a segunda é de natureza comparativa e será utilizada para exploração e análise de situações mais concretas.

Não existe uma frase consensual a todos os inquiridos (cfr. Apêndice 2). A afirmação que obteve um maior número de seleções, aproximadamente $78 \%$ dos inquiridos, foi a frase 2.3, relativa ao Modelo Cognitivo ("A IES encontra-se aberta à investigação e à autocrítica").

Salvaguarda-se, porém, que as frases 3.3 .2 e 5.2 foram selecionadas por, sensivelmente, $72 \%$ dos inquiridos. Estas duas frases diferenciam-se, apenas, por duas escolhas face à afirmação 2.3, o que revela não existir uma unanimidade referenciável.

Os dados coligidos parecem indicar que o Modelo Cognitivo foi aquele que obteve mais expressão no inquérito por questionário. Contudo, uma análise mais cuidada não corrobora essa perspectiva.

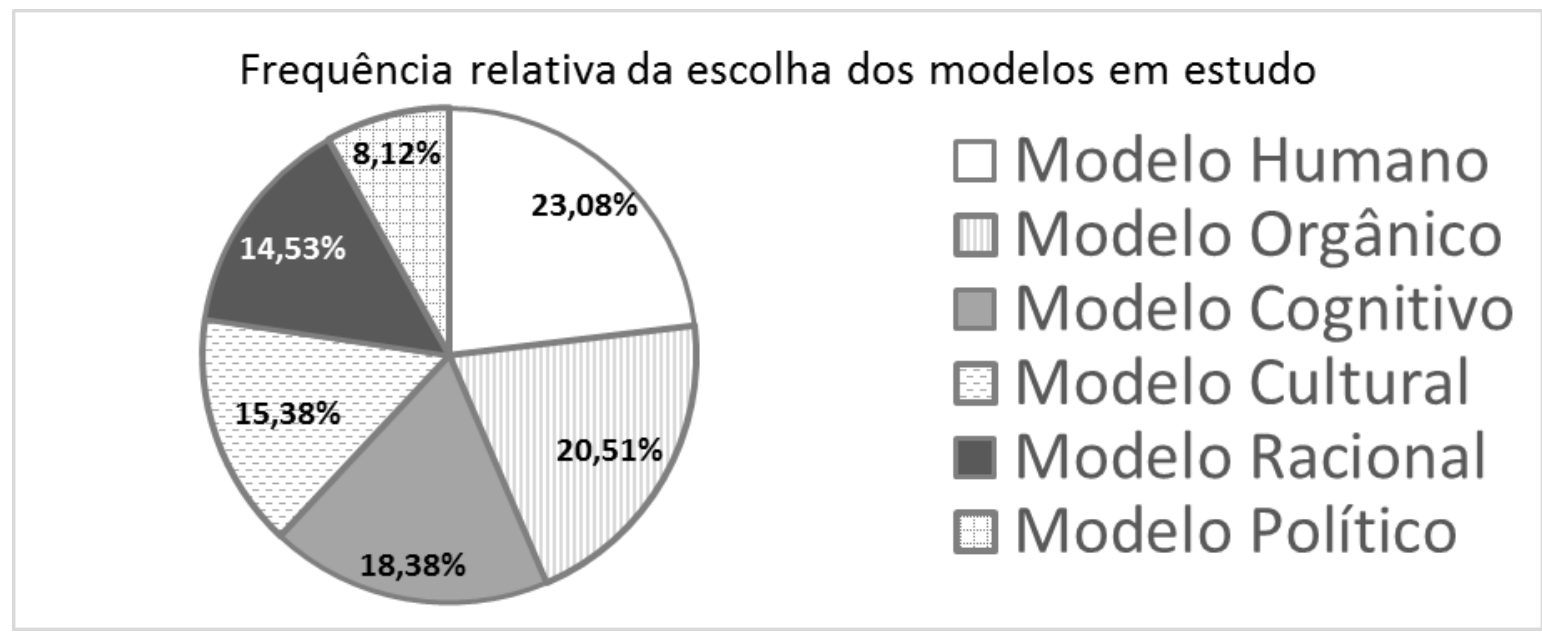

Gráfico 1. Distribuição da frequência relativa pelos modelos organizacionais

Ao agrupar-se e analisar-se os dados, tendo em consideração a relação das frases representativas com os modelos, o cenário altera-se significativamente. Como é possível verificar no Gráfico 1, o modelo organizacional que, de acordo com os inquiridos, apresenta maior relação com a realidade da Instituição de Ensino Superior em estudo é o Modelo Humano - A Escola como democracia. 
Ao considerar-se o somatório das afirmações apresentadas e agrupando-as pelos modelos correspondentes ${ }^{4}$, é possível verificar a tendência das escolhas em relação às metáforas em estudo. Optou-se por esta abordagem porque ao analisar situações isoladamente, não se torna possível identificar uma tendência ou conceptualizar uma metáfora integradora.

Face ao Gráfico 1, indicia-se que a metáfora escola como arena política é aquele que menos se adequa à realidade da IES, com uma representação de, aproximadamente, 8,12\% das afirmações selecionadas. Reconhece-se, por esse motivo, que este modelo poderá não possibilitar uma leitura suficientemente partilhada da realidade em estudo.

No polo oposto, com um percentil superior a $20 \%$, identifica-se que as metáforas escola como democracia $(23,08 \%)$ e escola como organismo vivo $(20,51 \%)$ foram aquelas que obtiveram maior representatividade na seleção dos inquiridos. Reconhece-se, assim, que os aspetos relacionados com estas duas metáforas foram identificados com maior ênfase pelos diferentes elementos da Escola Superior de Educação. Ainda que não seja possível generalizar estes resultados, torna-se claro que, no grupo dos inquiridos, estas duas metáforas são as que melhor representam e explicam o funcionamento da IES.

Ao analisar-se o Gráfico 2, verifica-se que, à exceção do Modelo Cultural, no grupo dos estudantes inquiridos e do Modelo Racional, no conjunto do pessoal não docente, o Modelo Humano e o Modelo Orgânico são aqueles que têm mais representatividade em todos os grupos. Assinala-se, ainda, que, mesmo quando estes dois modelos não são aqueles que apresentam maior frequência relativa, no geral dos três grupos em análise (docentes, discentes e pessoal não docente) continuam a ser modelos com elevada representatividade, situando-se sempre, e de forma transversal e intergrupal, entre os três modelos mais referenciados. A escolha, no âmbito destes dois modelos, varia consoante o grupo de referência, entre 17,74\% e $25,71 \%$, apresentado, deste modo e como já foi mencionado, uma tendência referenciável, mesmo quando não são os dois modelos mais escolhidos.

\footnotetext{
${ }^{4}$ Como as afirmações 3.3.1 e 3.3.2 são divisão de uma afirmação única, para o somatório, considerou-se que cada uma delas correspondia a metade $(0,5)$ do valor.
} 


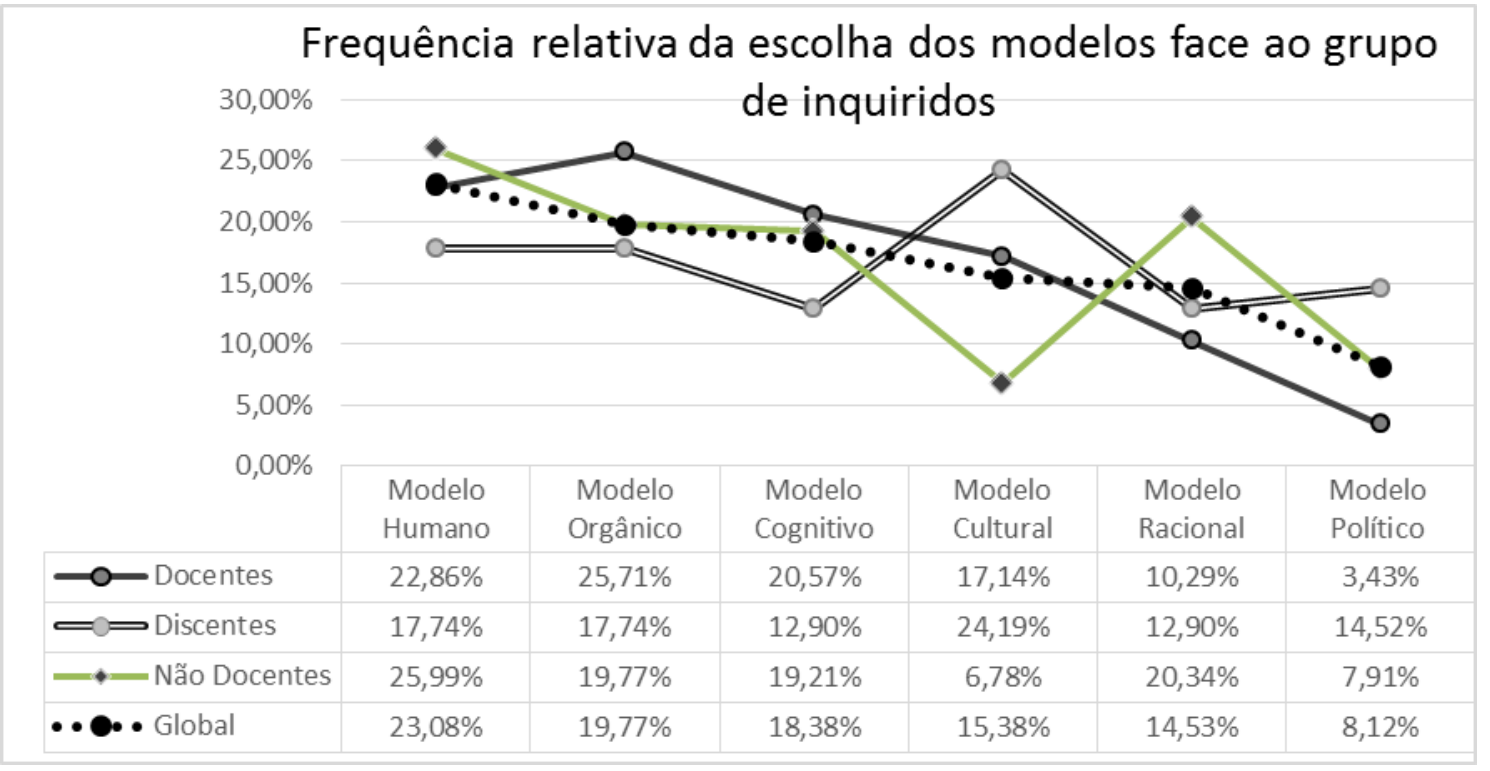

Gráfico 2. Frequência relativa da escolha dos modelos face ao grupo de inquiridos

Evidencia-se que a tendência de escolha para os dois modelos aludidos não se encontra circunscrita a um determinado grupo da IES. Transversalmente, os diferentes intervenientes da Instituição de Ensino Superior em estudo, reconhecem, em maior número, aspectos específicos dos modelos humano e orgânico. Desta forma, é possível indiciar-se que as metáforas escola como democracia e escola como organismo vivo são aquelas que, de acordo com os inquiridos, encontram mais representatividade na organização educativa em análise.

Todavia, reconhece-se que, face aos dados apresentados, os modelos que surgem com uma representatividade entre os $15 \%$ e os $20 \%$ necessitam de uma análise mais cuidada.

O Modelo Racional só é significativamente representativo no grupo dos inquiridos que pertencem ao corpo do pessoal não docente da IES em estudo. Tendo esse ponto em consideração, e reconhecendo que, nos restantes grupos, o modelo encontra-se com uma representação expressivamente inferior, não ultrapassando os 12,9\%, parece que os aspetos do modelo racional que encontram melhor representação na IES não são transversais. Face ao grupo dos inquiridos, mostra-se como plausível que este modelo apenas possa explicar aspetos do funcionamento dos serviços administrativos. Retomando o Apêndice 1, demonstra-se que os elementos do modelo racional que mais são identificáveis pelos inquiridos são a estrutura hierárquica e a centralização. Tomando em consideração o exposto, evidencia-se que, no contexto não pedagógico, os diferentes intervenientes reconhecem que a hierarquia e a centralização das decisões são elementos característicos da instituição.

Por fim, é necessário refletir sobre as metáforas, escola como cultura e escola como cérebro. Ainda que apresentem uma representação com uma diferença de três pontos percentuais, $15,38 \%$ e 18,38\%, respetivamente, o estudo não é tão linear como aparenta. 
Numa primeira análise, seria de esperar que o modelo cognitivo fosse aquele que, em comparação com o modelo cultural, apresentasse maior relevância para a interpretação e análise da organização. Contudo, os dados não se apresentam nesse sentido.

Quando os inquiridos necessitam de selecionar uma afirmação em detrimento de outra, $67,67 \%$ optou por considerar que um determinado aspeto do modelo cultural (afirmação 2.2) melhor corresponderia à verdade em relação a uma determinada característica do modelo cognitivo (afirmação 4.3), como é possível verificar no Gráfico 3. Alerta-se, porém, que, na primeira questão, as afirmações apresentam dados contraditórios.

\section{Frequência relativa face à escolha entre a afirmação $4.3 \mathrm{e}$}

2.2

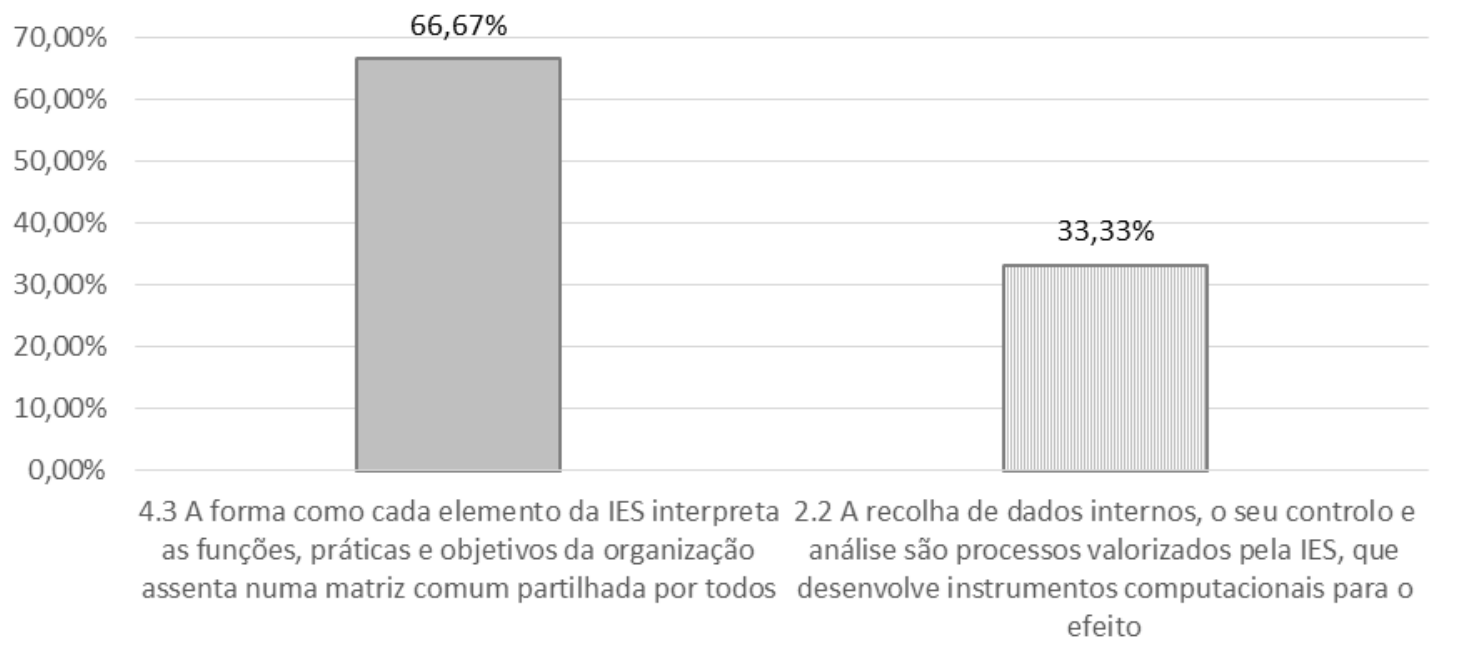

Gráfico 3. Frequência relativa face à escolha entre a afirmação 4.3 e 2.2

Como é demonstrado pelo Apêndice 2, na primeira questão, 13 dos inquiridos consideraram que a afirmação 4.3 se adequava à IES, enquanto, por sua vez, apenas 7 inquiridos reconheceram a afirmação 2.2 como característica da organização em estudo. Constata-se, portanto, que só quando estes elementos são confrontados, sendo necessário optar por um ou por outro, é que os inquiridos optam por escolher a frase representativa do modelo cultural.

Verifica-se, e tomando em consideração o Gráfico 2, que o grupo do pessoal não docente apresenta dados, no âmbito do modelo cultural, que não se coadunam com o que é escolhido pelos professores e estudantes. Os docentes, com uma percentagem de 17,14\%, como os discentes, com uma representação superior, de 24,19\%, reconhecem maior importância aos aspetos culturais da organização. Por sua vez, o corpo não docente não parece reconhecer estes elementos, identificando-os numa percentagem muito inferior face às anteriores, de apenas $6,78 \%$. 
Face ao aludido, os dados referentes ao modelo cultural apresentam dados muito variáveis, em função dos grupos. Tendo em consideração o observado, os dados aparentam evidenciar que os grupos com maior propensão para análise dos aspetos pedagógicos (professores e estudantes) valorizam elementos culturais da organização.

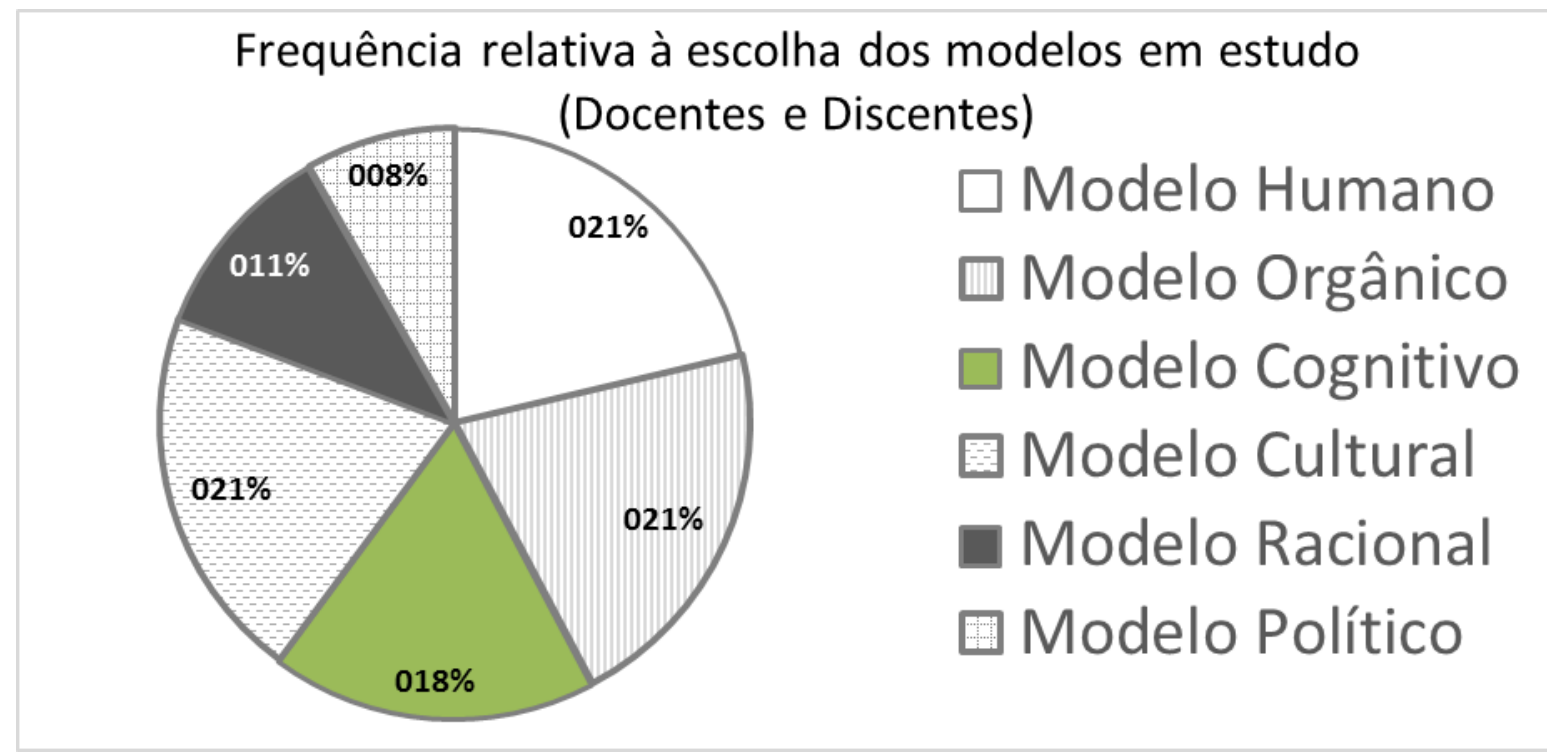

Gráfico 4. Distribuição da frequência relativa pelos modelos organizacionais (Docentes e Discentes)

Ao considerarem-se apenas os dados dos docentes e discentes, como é possível explorar no Gráfico 4, verifica-se um panorama diferente do que foi apresentado com o Gráfico 1. Ainda que os Modelos Humano e Orgânico sejam os que continuam com maior representatividade, o Modelo Cultural assume-se com especial preponderância, sendo o terceiro modelo mais representado, com uma distância considerável do Modelo Cognitivo, que aparece em quarto lugar.

Desta forma reconhece-se, claramente, que o Modelo Cultural, para os professores e estudantes, é identificável como um aspeto relevante da Instituição de Ensino Superior em estudo. Em concordância com estes dados, é possível afirmar-se que o modelo cultural tem especial importância para explicar o funcionamento da organização, mas numa perspectiva pedagógica. Induz-se, portanto, que é possível identificar o modus operandi, sustentado em valores e construções culturais, da ação pedagógica na IES. Sendo a instituição em estudo uma organização educativa, é um aspeto basilar para compreender e analisar. Em suma, os inquiridos parecem reconhecer uma cultura pedagógica que é própria e característica da Instituição de Ensino Superior em estudo, que lhe confere unicidade, identidade e uma matriz para a ação pedagógica. 


\title{
UMA METÁFORA EXPLICATIVA: A ESCOLA COMO CASA NA ÁRVORE
}

Tomando a análise feita na secção anterior, verifica-se que os dois modelos que melhor podem explicar o funcionamento da IES em estudo são: Modelo Humano e Modelo Orgânico. A par destes dois elementos, reconhece-se a importância do Modelo Cultural para o funcionamento pedagógico da Instituição de Ensino Superior em estudo, pelo que não deve ser ignorado o seu contributo na construção de uma metáfora explicativa. Tendo em conta esse objetivo, considerou-se que a IES pode corporizar a metáfora: escola como casa na árvore.

Como é possível verificar pela notícia de Chaves (2013), a construção arquitetónica das casas na árvore são, em si mesmo, um elemento cultural. É ao encarar-se a casa da árvore como um projeto e resultado cultural que se consegue perceber a sua individualidade. Na IES em estudo, como já foi mencionado, há um elemento basilar no qual é possível reconhecer uma cultura própria: a ação pedagógica. De forma homóloga ao aspeto cultural das casas nas árvores, é um elemento que nem sempre é facilmente reconhecido/reconhecível, mas apresenta-se como fundamental para se perceber a sua singularidade e unicidade, afirmandose, por isso, como uma matriz característica tanto das casas nas árvores como da IES. Tendo esta perspectiva como base, é possível perceber de que forma o Modelo Cultural explica e se implica no funcionamento da Instituição de Ensino Superior em estudo.

O Modelo Orgânico explica outros elementos da organização. Como referem Alperstedt, Martignago e Fiates (2006, p. 115), não é possível ignorar que

\begin{abstract}
uma organização complexa como a universidade requer atenção a uma série de fatores os quais muitas das vezes, pelas inúmeras interações existentes, tornam-se incontroláveis. Muitos são os fatores do ambiente que geram impactos nas organizações universitárias retirando cada vez mais do seu dia-a-dia a crença pela certeza. Além de todas as forças que comumente afetam as demais organizações, as universidades passam por dificuldades decorrentes da própria expansão do ensino superior e da intervenção normativa do governo, tanto na sua organização quanto no seu funcionamento.
\end{abstract}

Esses elementos também foram reconhecidos pelos inquiridos. Como se verifica no Apêndice 2 , mais de $70 \%$ dos inquiridos consideram que a IES é influenciada pelo contexto em que se encontra inserida e pelas diferentes organizações desse contexto. Por sua vez, menos de $35 \%$ das pessoas que responderam ao inquérito identificaram que a IES influenciava o contexto e as restantes organizações. De forma paralela, parece mais evidente que uma casa na árvore seja influenciada pelo ambiente e contexto (sol, chuva, passagem do tempo, crescimento das árvores,...).

Contudo, também se reconhece que a IES em estudo influência o contexto, nomeadamente na formação contínua e de especialização, que terá repercussões nas escolas básicas e secundárias da área adjacente. Da mesma forma, talvez de um modo menos óbvio, uma casa

\begin{tabular}{|l|l|l|l|l|l|} 
(C) Rev. Inter. Educ. Sup. & Campinas, SP & v.4 & n.1 & p.197-220 & jan./abr. 2017 \\
\hline
\end{tabular}


na árvore influencia o meio em que está inserida (confere mais sombra, influi o crescimento das árvores, serve de abrigo e de ninho para diferentes espécies,...). Pondere-se, ainda, que mais de $65 \%$ dos inquiridos reconhecem a adaptabilidade da IES face ao contexto e à passagem do tempo. Parece evidente que, mais não seja pelo processo de erosão, as casas na árvore têm a necessidade de se atualizar e adaptar ao ambiente em que estão inseridas, para evitarem o risco de ruírem. Em concordância com o que foi aludido, verifica-se que a metáfora da escola como casa na árvore parece corresponder ao modelo orgânico. Há, porém, um aspeto ainda não referenciado, a comunicação interna entre os diferentes grupos da IES, por forma a resolver problemas comuns à organização. De acordo com as respostas obtidas, apenas $31 \%$ dos inquiridos evidenciaram reconhecer este aspeto como característico da instituição em estudo. Não sendo possível transpor de forma exata este elemento para a metáfora da escola como casa na árvore, reconhece-se um outro aspeto que pode complementar esta dimensão. Tendo em conta que as casas nas árvores são, por norma, habitações que se encontram mais isoladas, é necessário que os diferentes sistemas internos (eletricidade, água, canalização,...) funcionem de forma conjunta. Tendencialmente, estes aspetos são menos visíveis, mas sem os mesmos a habitabilidade da casa seria posta em causa. De forma semelhante, os diferentes serviços e grupos da IES (professores, serviços administrativos, serviços académicos,...) necessitam de, por vezes informalmente, trabalhar em conjunto de modo a corresponder às necessidades da instituição.

O último modelo em análise é o Modelo Humano. Aludindo ao que já foi referido neste âmbito, verifica-se que, de acordo com esta perspectiva, as necessidades dos diferentes intervenientes é fundamental para o bem-estar dos mesmos e para a sua produtividade no interior da organização. Sistematicamente, e retomando o Gráfico 2, os diferentes intervenientes da organização reconheceram que há uma preocupação humana para com os elementos da instituição. Esta situação perpetua a noção de complementaridade entre os objetivos e missão da IES em estudo e os objetivos individuais de cada um dos membros da organização. Claramente, a ideia de casa na árvore relaciona-se com as relações humanas, com o cumprimento de sonhos e desejos e com o bem-estar de quem lhe faz uso. A casa na árvore apresenta-se como uma ideia que representa a execução de ambições pessoais, numa contínua procura para satisfazer as diferentes necessidades de cada um. Como foi reconhecido por mais de $70 \%$ dos inquiridos, a IES salvaguarda, na medida do possível, a comodidade dos seus elementos, contribuindo o seu bem-estar.

No âmbito da metáfora escolhida, também se torna claro que a perpetuação da casa na árvore, nas melhores condições, depende, obrigatoriamente de quem faz uso dela. Tendo em consideração que, como já foi mencionado, as casas nas árvores se encontram vulneráveis aos diferentes elementos naturais, a sua sobrevivência depende, exclusivamente, da sua manutenção por parte dos elementos humanos. Essa vontade de, contínua e progressivamente, trabalhar em prol da manutenção da casa na árvore depende, obrigatoriamente, do bem-estar dos diferentes membros que partilham o espaço da casa. Se a habitação não possibilitar uma 
gradual resposta às necessidades de quem lhe faz uso, progressivamente as pessoas desmotivar-se-ão de trabalhar para a manter. Em consonância com esta perspectiva, mais de $45 \%$ das pessoas que responderam ao inquérito por questionário reconhecem que "a IES faz os possíveis para conciliar os objetivos da organização com os objetivos individuais e pessoais de cada um dos seus elementos, promovendo, por isso, o bem-estar de todos".

Face ao explorado, evidencia-se que a metáfora 'escola como casa na árvore' possibilita corresponder aos principais aspetos identificados pelos inquiridos. Salvaguarda-se, porém, que esta imagem apresenta um aspeto que não se coaduna com a realidade da IES: a sua finalidade. Ainda que, através da metáfora escola como casa na árvore, se identifiquem os aspetos relacionados com a cultura pedagógica, com a forma como esta se relaciona com o contexto em que está inserida e com o cuidado que tem com os seus membros, ignora a sua função externa.

\section{INDICAÇõES FINAIS}

Através deste trabalho, e mesmo com um número reduzido de inquiridos, foi possível perceber as principais tendências na forma como os diferentes grupos de estatuto da IES em estudo encaram e analisam a instituição a que pertencem e, desse modo, elaborar uma metáfora explicativa dessa realidade social.

Seria relevante continuar o estudo, aumentando o número de pessoas inquiridas e articulando com entrevistas a diferentes representantes de cada um dos grupos em_análise (docentes, discentes e pessoal não docente). Seria ainda de interesse replicar o estudo em outras instituições do ensino superior, de modo a perceber-se a pertinência do estudo e da metáfora construída.

Salvaguarda-se, porém, que os dados recolhidos possibilitaram a elaboração de uma metáfora que, no seu essencial, corresponde aos aspetos que foram identificados, por parte dos inquiridos, com maior preponderância. Ainda que não seja uma metáfora clássica,_possibilita ilustrar e identificar os elementos que, de acordo com os elementos da instituição, têm maior relevância, visibilidade e implicação no quotidiano da organização.

\section{REFERÊNCIAS}

ALPERSTEDT, G. D.; MARTIGNAGO, G.; FIATES, G. G. S. O processo de adaptação estratégica em uma Instituição de Ensino Superior sob a ótica da teoria institucional. Revista de Ciências da Administração, v. 8, n. 15, p. 114-137, 2006. Disponivel em: <http://dx.doi.org/10.5007/1675>. 
BASSEY, M. Case study research. In: SWANN, J.; PRATT, J. Educational research in practice: making sense of methodology. London: Continuum, 2003. p. 111-123.

BASTOS, A. V. B. et al. Teoria implícita de organização e padrões de inovação nos processos de gestão. Psicologia: Reflexão e Crítica, v. 20, n. 1, p. 157-166, 2007.

BERTALANFFY, L. V. General system theory: foundations, development, applications. New York: George Braziller, 1969. Disponivel em:

<http://monoskop.org/images/7/77/Von_Bertalanffy_Ludwig_General_System_Theory_1968 .pdf $>$.

BRANDT, N. C. Constructing school organization through metaphor: making sense of school reform. Florida State University. Florida. 2004.

BUSH, T. Theories of educational management, p. 1-25, 2006. Disponivel em:

$<$ http://cnx.org/content/m13867/1.1/>.

COSTA, J. A. Imagens organizacionais da escola. Porto: Edições ASA, 1996.

CRAIG, C. J. The epistemic role of novel metaphors in teachers' knowledge constructions of school reform. Teachers and Teaching, v. 11, n. 2, p. 195-208, 2005.

CUNHA, M. P. E. Organizações: da pluralidade das concepções a uma meta-metáfora plurista. Organizações e Trabalho, v. 13, p. 55-73, 1995.

DUARTE, P. A construção de comunidades educativas e pedagógicas: Para uma formação e prática pedagógica articulada. Revista Internacional de Educação Superior, Campinas, SP, v. 2, n. 3, p. 405-429, 2016.

FERREIRA, S. M. D. C. A Estruturação díptica da gramática de regras do agrupamento de escolas como organização. Universidade do Minho. Braga. 2004.

FROTA, A. P. D. R. A. Gestão escolar e culturas docentes: o público e o privada em análise. Universidade de Aveiro. Aveiro. 2011.

HODGKINSON, G. P.; HEALEY, M. P. Cognition in organizations. Annual Review of Psychology, v. 59, p. 387-417, 2008.

JENSEN, D. F. N. Metaphors as a bridge to understanding educational and social contexts. International Journal of Qualitative Methods, v. 5, n. 1, p. 1-17, 2006. Disponivel em: <https://www.ualberta.ca/ iiqm/backissues/5_1/PDF/JENSEN.PDF>.

LIMA, L. C. A "escola” como categoria na pesquisa em educação. Educação Unisinos, v. 12 , n. 2, p. 82-88, 2008a.

LIMA, L. C. Prefácio. In: LIMA, L. C. A escola como organização educativa: uma abordagem sociológica. São Paulo: Cortez Editora, 2008b. p. 7-14.

\begin{tabular}{l|l|l|l|l}
\hline (C) Rev. Inter. Educ. Sup. & Campinas, SP & v.4 & n.1 & p.197-220
\end{tabular} jan./abr. 2017 
MCGREGOR, D. The human side of enterprise. The Management Review, v. 46, n. 2, p. 22-28, 1957.

MEYER, J. W.; SCOTT, W. R.; DEAL, T. E. Institutional and technical sources of organizational structure explaining the structure of educational organizations. Institute for Research on Educational Finance and Governance, p. 5-35, 1980.

MORGAN, G. Imagens da organização: edição executiva. Tradução de Geni G. Goldschmidt. 2. ed. São Paulo: Atlas, 2002.

MOUTINHO, J. A. S. O impacto dos cursos de educação e formação: estudo de caso. Universidade de Coimbra. Coimbra. 2012.

NICOLINI, D. Comparing methods for mapping organizational cognition. Organization Studies, v. 20, n. 5, p. 833-860, 1999.

NÓVOA, A. Para uma análise das instituições escolares. As organizações escolares em análise, v. 3, p. 3-14, 1992. Disponivel em:

<http://www.escolabarao.com.br/pdf/texto2/files/publication.pdf>.

SCHNEIDER, S. C.; ANGELMAR, R. Cognition in organizational analysis: who's minding the store? Organization Studies, v. 14, n. 3, p. 347-374, 1993.

SCHWANINGER, M. A Cybernetic model to enhance organizational intelligence. Systems Analysis Modelling Simulation, v. 43, n. 1, p. 53-65, 2003.

SOREANU, R. Metaphor in the social sciences: creative methodologies and some elements for an epistemological reconstruction. Studia Universitatis Babes-Bolyai-Sociologia, n. 1, p. 239-256, 2010. Disponivel em: <http://socasis.ubbcluj.ro/metodologie/wpcontent/upload/articole/Soreanu\%20(2010).pdf $>$.

TAN, M.; HEE, T. F.; PIAW, C. Y. A Qualitative analysis of the leadership style of a ViceChancellor in a private university in Malaysia. SAGE Open, p. 1-11, 2015.

TORRES, L. L. Cultural organizacional escolar: apogeu investigativo no quadro de emergência das políticas neoliberais. Educação Social, v. 28, n. 98, p. 151-179, 2007.

TRIGO, J. R.; COSTA, J. A. Liderança nas organizações educativas: a direcção por valores. Ensaio: avaliação e políticas públicas em educação, Rio de Janeiro, v. 16, n. 61, p. 561-582, 2008. 


\section{APÊNDICES}

Apêndice 1 - Frases representativas de cada um dos modelos

\begin{tabular}{|c|c|}
\hline Modelo & Frases representativas dos modelos \\
\hline 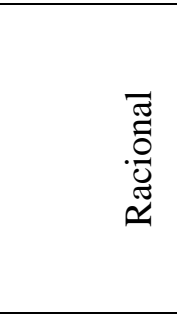 & $\begin{array}{l}\text { 1.1 A IES é fortemente marcada por uma estrutura hierárquica, centralizada e } \\
\text { devidamente formalizada; } \\
\text { 1.2 A IES promove a uniformidade e a impessoalidade das relações humanas no } \\
\text { interior da organização } \\
\text { 1.3 A IES centra a sua ação na regulamentação rigorosa, na divisão e } \\
\text { especialização do trabalho, promovendo uma ação rotineira centrada na } \\
\text { burocracia e no cumprimento de normas }\end{array}$ \\
\hline 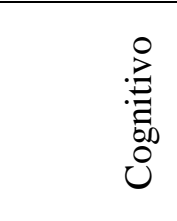 & $\begin{array}{l}\text { 2.1 A informação interna, e a circulação da mesma entre os diversos } \\
\text { departamentos da instituição, são altamente valorizados na IES } \\
\text { 2.2 A recolha de dados internos, o seu controlo e análise são processos } \\
\text { valorizados pela IES, que desenvolve instrumentos computacionais para o efeito } \\
\text { 2.3 A IES encontra-se aberta à investigação e à autocrítica }\end{array}$ \\
\hline 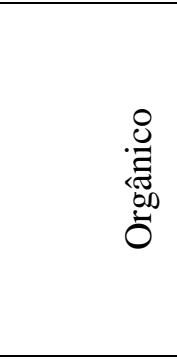 & $\begin{array}{l}\text { 3.1 Tendo como objetivo estimular a inovação e a resolução de problemas, a IES } \\
\text { promove a comunicação entre os diversos departamentos da instituição } \\
\text { 3.2 A IES adapta-se, progressivamente, ao contexto, ao meio envolvente e à } \\
\text { passagem do tempo } \\
\text { 53.3.1 A IES é influenciada pelo contexto em que está inserida, por outras } \\
\text { organizaçoes e pela comunidade em geral } \\
\text { 3.3.2 A IES influencia o contexto em que está inserida, as outras organizações e } \\
\text { a comunidade em geral }\end{array}$ \\
\hline $\begin{array}{l}\underset{\overparen{T}}{\Xi} \\
\stackrel{\Xi}{\Xi}\end{array}$ & $\begin{array}{l}\text { 4.1 É possível reconhecer as ideologias, valores, tradições e rituais que são } \\
\text { consensuais e caracterizam a IES } \\
4.2 \text { São identificáveis os valores e as práticas comuns que se afirmam como } \\
\text { basilares para a relação entre os diferentes intervenientes e para a ação de cada } \\
\text { um deles no interior da IES } \\
\text { 4.3 A forma como cada elemento da IES interpreta as funções, práticas e } \\
\text { objetivos da organização assenta numa matriz comum partilhada por todos }\end{array}$ \\
\hline $\begin{array}{l}\stackrel{̊}{\Xi} \\
\stackrel{\Xi}{\Xi} \\
\text { 吾 }\end{array}$ & $\begin{array}{l}\text { 5.1 A IES tem em consideração os seus funcionários, fazendo os possíveis para } \\
\text { que os mesmos se sintam úteis, autónomos, valorizados e reconhecidos } \\
5.2 \text { Na IES, são salvaguardados, na medida do possível, os interesses e } \\
\text { necessidades de cada um dos seus elementos } \\
\text { 5.3 A IES faz os possíveis para conciliar os objetivos da organização com os } \\
\text { objetivos individuais e pessoais de cada um dos seus elementos, promovendo, } \\
\text { por isso, o bem-estar de todos }\end{array}$ \\
\hline $\begin{array}{l}\stackrel{0}{\Xi} \\
\stackrel{0}{0}\end{array}$ & $\begin{array}{l}\text { 6.1 O ambiente na IES desenvolve-se através da conflitualidade de interesses e } \\
\text { na consequente luta pelo poder } \\
\text { 6.2 As palavras-chave, nos discursos da IES, são: interesse, conflitos, poder e } \\
\text { negociação } \\
\text { 6.3 As decisões na IES são, no seu essencial, tomadas através do processo de } \\
\text { negociações, sustentadas no poder e na influência dos diversos indivíduos e } \\
\text { grupos da instituição }\end{array}$ \\
\hline
\end{tabular}

${ }^{5}$ A frase 3.3 foi subdividida em duas: 3.3.1 e 3.3.2. Optou-se por esta estrutura, uma vez que se considerou que, embora ser influenciada e influenciar o meio sejam conceitos diferentes, no âmbito da metáfora analisada eles apresentam-se com igual importância, uma vez que revelam que há uma relação de simbiose ou de antibiose entre o meio e as organizações.

\begin{tabular}{|l|l|l|l|l|l|} 
(C) Rev. Inter. Educ. Sup. & Campinas, SP & v.4 & n.1 & p.197-220 & jan./abr. 2017 \\
\hline
\end{tabular}


Apêndice 2 - Frequência absoluta do número de vezes que cada frase foi selecionada na questão 1. do inquérito por questionário e percentil de escolhas em relação ao total de inquiridos

\begin{tabular}{|c|c|c|}
\hline Frases representativas dos modelos & $\begin{array}{l}\text { Frequência } \\
\text { absoluta }\end{array}$ & Percentil \\
\hline 2.3 A IES encontra-se aberta à investigação e à autocrítica & 25 & $78,13 \%$ \\
\hline $\begin{array}{l}\text { 3.3.2 A IES é influenciada pelo contexto em que está inserida, por } \\
\text { outras organizações e pela comunidade em geral }\end{array}$ & 23 & $71,88 \%$ \\
\hline $\begin{array}{l}\text { 5.2 Na IES, são salvaguardados, na medida do possível, os interesses } \\
\text { e necessidades de cada um dos seus elementos }\end{array}$ & 23 & $71,88 \%$ \\
\hline $\begin{array}{l}\text { 3.2 A IES adapta-se, progressivamente, ao contexto, ao meio } \\
\text { envolvente e à passagem do tempo }\end{array}$ & 21 & $65,63 \%$ \\
\hline $\begin{array}{l}\text { 1.1 A IES é fortemente marcada por uma estrutura hierárquica, } \\
\text { centralizada e devidamente formalizada }\end{array}$ & 17 & $53,13 \%$ \\
\hline $\begin{array}{l}\text { 4.1 É possível reconhecer as ideologias, valores, tradições e rituais } \\
\text { que são consensuais e caracterizam a IES }\end{array}$ & 17 & $53,13 \%$ \\
\hline $\begin{array}{l}\text { 5.1 A IES tem em consideração os seus funcionários, fazendo os } \\
\text { possíveis para que os mesmos se sintam úteis, autónomos, } \\
\text { valorizados e reconhecidos }\end{array}$ & 16 & $50,00 \%$ \\
\hline $\begin{array}{l}\text { 5.3 A IES faz os possíveis para conciliar os objetivos da organização } \\
\text { com os objetivos individuais e pessoais de cada um dos seus } \\
\text { elementos, promovendo, por isso, o bem-estar de todos }\end{array}$ & 15 & $46,88 \%$ \\
\hline $\begin{array}{l}2.2 \text { A recolha de dados internos, o seu controlo e análise são } \\
\text { processos valorizados pela IES, que desenvolve instrumentos } \\
\text { computacionais para o efeito }\end{array}$ & 13 & $40,63 \%$ \\
\hline $\begin{array}{l}\text { 6.3 As decisões na IES são, no seu essencial, tomadas através do } \\
\text { processo de negociações, sustentadas no poder e na influência dos } \\
\text { diversos indivíduos e grupos da instituição }\end{array}$ & 13 & $40,63 \%$ \\
\hline $\begin{array}{l}\text { 4.2 São identificáveis os valores e as práticas comuns que se afirmam } \\
\text { como basilares para a relação entre os diferentes intervenientes e para } \\
\text { a ação de cada um deles no interior da IES }\end{array}$ & 12 & $37,50 \%$ \\
\hline $\begin{array}{l}\text { 3.3.1 A IES influencia o contexto em que está inserida, as outras } \\
\text { organizações e a comunidade em geral }\end{array}$ & 11 & $34,38 \%$ \\
\hline $\begin{array}{l}3.1 \text { Tendo como objetivo estimular a inovação e a resolução de } \\
\text { problemas, a IES promove a comunicação entre os diversos } \\
\text { departamentos da instituição }\end{array}$ & 10 & $31,25 \%$ \\
\hline $\begin{array}{l}\text { 1.3 A IES centra a sua ação na regulamentação rigorosa, na divisão e } \\
\text { especialização do trabalho, promovendo uma ação rotineira centrada } \\
\text { na burocracia e no cumprimento de normas }\end{array}$ & 9 & $28,13 \%$ \\
\hline $\begin{array}{l}\text { 1.2 A IES promove a uniformidade e a impessoalidade das relações } \\
\text { humanas no interior da organização }\end{array}$ & 8 & $25,00 \%$ \\
\hline $\begin{array}{l}\text { 4.3 A forma como cada elemento da IES interpreta as funções, } \\
\text { práticas e objetivos da organização assenta numa matriz comum } \\
\text { partilhada por todos }\end{array}$ & 7 & $21,88 \%$ \\
\hline $\begin{array}{l}\text { 2.1 A informação interna, e a circulação da mesma entre os diversos } \\
\text { departamentos da instituição, são altamente valorizados na IES }\end{array}$ & 5 & $15,63 \%$ \\
\hline 6.1 O ambiente na IES desenvolve-se através da conflitualidade de & 5 & $15,63 \%$ \\
\hline
\end{tabular}

\begin{tabular}{l|l|l|l|l|l} 
(C) Rev. Inter. Educ. Sup. & Campinas, SP & v.4 & n.1 & p.197-220 & jan./abr. 2017
\end{tabular}




\begin{tabular}{|l|c|l|}
\hline interesses e na consequente luta pelo poder & & \\
\hline $\begin{array}{l}\text { 6.2 As palavras-chave, nos discursos da IES, são: interesse, conflitos, } \\
\text { poder e negociação }\end{array}$ & 1 & $3,13 \%$ \\
\hline
\end{tabular}

\section{${ }^{\mathrm{i}}$ Sobre os autores}

\section{Pedro Duarte}

E-mail: pedropereira@ese.ipp.pt / ORCID: http://orcid.org/0000-0002-3048-6959

Escola Superior de Educação do Politécnico do Porto - Portugal

Doutorando em Educação pela Universidade de Santiago de Compostela (Espanha).

\section{Fernando Diogo}

E-mail: fdiogo@ese.ipp.pt / ORCID: http://orcid.org/0000-0002-7178-7889

Escola Superior de Educação do Politécnico do Porto - Portugal

Doutor em Educação pela Universidade do Porto. 